\title{
Extinction of taste aversion does not eliminate taste potentiation of odor aversion in rats or color aversion in pigeons
}

\author{
BOW TONG LETT \\ Memorial University of Newfoundland, St. Johns, Newfoundland, Canada
}

\begin{abstract}
Rats were exposed to an odor-taste compound prior to being poisoned with lithium chloride on two occasions in Experiment 1 but only once in Experiment 2. Then, in each experiment, one group was given unreinforced exposures to the taste cue until extinction of the conditioned taste aversion occurred. During a later test, taste potentiation of odor aversion was obtained to a similar extent whether or not the taste aversion had been extinguished. An analogous finding was obtained with pigeons in Experiment 3. The present results indicate that taste potentiation does not depend on an underlying conditioned taste aversion, and, therefore, they support the notion that taste strengthened the odor-sickness (or color-sickness) association during the conditioning process.
\end{abstract}

When a compound composed of a strong and a weak CS is presented prior to a US, the strong CS tends to prevent the conditioning of the weak CS. This phenomenon, called overshadowing by Pavlov (1927), has been observed in a wide variety of learning situations. It occurs in both classical (e.g., Pavlov, 1927) and instrumental conditioning (e.g., Miles \& Jenkins, 1973); it occurs in what might be called arbitrary conditioning situations, such as CER (e.g., Kamin, 1969), as well as in more "natural" situations, such as poison-avoidance learning (e.g., Revusky, 1971). Indeed, so ubiquitous is the phenomenon that it is thought to reflect a general principle of learning (e.g., Rescorla \& Wagner, 1972; Revusky, 1971 ).

An important exception to overshadowing has recently been observed in poison-avoidance learning of both birds (e.g., Brett, Hankins, \& Garcia, 1976; Clarke, Westbrook, \& Irwin, 1979; Lett, 1980; Westbrook, Clarke, \& Provost, 1980) and rats (e.g., Galef \& Osborne, 1978; Rusiniak, Hankins, Garcia, \& Brett, 1979; Westbrook, Homewood, Horn, \& Clarke, 1983). This exception, called the taste potentiation effect, can be demonstrated by presenting a weak CS, such as odor for rats or color for birds, in compound with a strong CS, taste, prior to the US of sickness. The resulting conditioned aversion to the odor or color CS is usually enhanced relative to that obtained when the odor or color cue is presented by itself prior to induction of sickness.

There are two ways of explaining these enhanced odor and color aversions. One view (Galef \& Osborne, 1978;

This research was supported in part by a grant from the Natural Sciences and Engineering Research Council, Canada. I thank Sam Revusky for reading the manuscript and Anne Dawe for her invaluable technical assistance.

The author's mailing address is: Department of Psychology, Memorial University, St. Johns, Newfoundland, Canada A1B $3 \times 9$.
Garcia \& Rusiniak, 1980; Palmerino, 1979; Palmerino, Rusiniak, \& Garcia, 1980; Rusiniak et al., 1979) is that the presence of the taste CS during conditioning increases the strength of the odor-sickness (or color-sickness) association. This process has been called synergistic compound potentiation (Rusiniak et al., 1979) and associative potentiation (Lett, 1984).

The second possibility (Clarke et al., 1979; Durlach \& Rescorla, 1980; Palmerino, 1979) is that the odor (or color) aversion is enhanced by means of a process similar to that presumed to account for sensory preconditioning. During training, the presentation of the odor-taste compound prior to induction of sickness results in an odortaste association as well as associations between odor and sickness and between taste and sickness. Thus, the presentation of the odor during the test activates not only the odor-sickness association but also the odor-taste association, leading to the activation of the taste-sickness association. The activated odor-sickness and taste-sickness associations summate in depressing the animal's intake of the odorized water. This summation effect should be critically dependent on the formation and maintenance of a strong conditioned taste aversion. In contrast, an enhancement of the odor (or color) aversion produced by associative potentiation should be independent of the conditioned taste aversion, since the presence of the taste cue is assumed to result in the strengthening of the odor-sickness (or color-sickness) association during the conditioning process.

The weight of evidence favors the associative potentiation hypothesis. Enhanced aversions produced by compounding odor with taste do not depend on the formation (Kiefer, Rusiniak, \& Garcia, 1982) or the maintenance (Palmerino, 1979) of the conditioned taste aversion. Kiefer et al. showed that an enhancement of odor aversion can occur in the absence of any detectable conditioning of the taste aversion. Rats with lesions of the gusta- 
tory neocortex were given pairings of an odor-taste (almond and saccharin) compound with poisoning. These lesions had been previously shown to severely disrupt conditioning of saccharin aversions without substantially affecting the detection of the saccharin taste (Braun, Slick, \& Lorden, 1972). Although the lesions did totally block the development of the saccharin aversions, the rats showed enhanced almond aversions relative to the appropriate controls.

Palmerino (1979) has shown that extinction of the conditioned taste aversion does not eliminate the enhancement of odor aversion produced by compounding odor with taste during conditioning. Her rats were given two conditioning trials in which an odor-taste compound, almond and saccharin, was paired with delayed lithium poisoning; the odor CS was presented on a disk surrounding the spout from which the saccharin water was drunk. Prior to the test for odor aversion, one of these groups received unreinforced exposures to the saccharin water presented without the odor CS until the taste aversion had extinguished. Then the two groups were tested with the odor CS presented on the disk, but in conjunction with unflavored water. Although previous work had indicated that rats do not show odor aversions when conditioned with odor in the absence of taste under these conditions, both groups exhibited marked odor aversions, as measured by a nearly complete suppression of water drinking in the presence of the almond odor during the first few tests. Thereafter, however, the rats with extinguished taste aversions did show faster extinction of the odor aversion, suggesting that the taste aversion may have contributed to the strength of the potentiation effect.

The above findings provide considerable support for the hypothesis of associative potentiation. The purpose of the present experiments was to provide further support by replicating the findings of Palmerino (1979) in rats and extending them to birds.

\section{EXPERIMENT 1}

The procedure of Experiment 1 was similar in its essential details to that used by Palmerino (1979). Rats were given two training trials in which an odor-taste compound was followed by delayed lithium poisoning, and then half of the rats were subjected to unreinforced exposures to the taste cue. The only important modification was the inclusion of a control group that received the odor cue with unflavored water prior to lithium poisoning during the two conditioning trials.

\section{Method}

Subjects. Forty adult male Sprague-Dawley rats, weighing a mean of $202 \mathrm{~g}$ at the start of the experiment, were the subjects. Throughout the entire experiment, these rats were given only deionized water.

Apparatus. The experimental chambers were 10 stainless steel cages taken from a standard rack of rat cages. Each cage had a lid and was placed on a tray that was used to catch the rat's droppings. The 10 cages were placed side by side, with a separation of a few inches, on a table in the same room with the rack in which the rats were housed.
In the experimental chamber, water and other fluids were delivered in a calibrated glass tube that had a metal spout with a disk surrounding its tip (Palmerino, 1979; Palmerino et al., 1980). The disk was made from a small plastic cap $(3.1 \mathrm{~cm}$ in diameter), obtained from a container used commercially to package a 10-cc syringe. The odor CS was delivered on a piece of filter paper placed inside this cap. To prevent the rats from getting access to the odorized filter paper, a metal screen was placed over the rim of the cap so that the tube protruded through the middle of the cap just past the rim.

Procedure. The rats were placed on water deprivation and gradually accustomed over a period of 1 week to receiving access to deionized water for $10 \mathrm{~min}$ in the experimental chamber, and approximately $2 \mathrm{~h}$ later, for $15 \mathrm{~min}$ in the home cage. The disk was unodorized on these occasions. Then the rats were divided into four groups matched in mean water consumption on the day prior to conditioning.

The rats were subjected to two conditioning trials separated by 2 days, during which they were maintained on their usual drinking schedule. On each conditioning trial, the rats in Groups OT-Ext and OT-No Ext received $.1 \% \mathrm{w} / \mathrm{v}$ saccharin solution in the presence of almond odor for $10 \mathrm{~min}$ and then returned to the home cage. The almond odor was produced by placing filter paper saturated with $.2 \mathrm{ml}$ of Schwartz's almond extract in the disk surrounding the tip of the drinking tube. Thirty minutes later, these rats were injected with $1 \mathrm{ml}$ of $.3 \mathrm{~N}$ lithium chloride for each $100 \mathrm{~g}$ of body weight. In a third group, Group $\mathrm{O}$, the rats drank unflavored water in the presence of the almond odor for $10 \mathrm{~min}$; this was followed 30 min later by an injection of lithium chloride. A final group, No $\mathrm{Li}$, also drank unflavored water in the presence of the almond odor but received no injections.

After several recovery days, the rats in Groups OT-Ext and No Li received an unreinforced exposure to saccharin solution in the absence of the odor cue for $10 \mathrm{~min}$ in the experimental chambers. Then, $2 \mathrm{~h}$ later, these rats were given $21 \mathrm{~h}$ of continuous access to saccharin solution in the home cage. On the following 3 days, they were given additional unreinforced exposures to the saccharin solution for $10 \mathrm{~min}$ each day in the experimental chambers, followed approximately $2 \mathrm{~h}$ later by $15 \mathrm{~min}$ access to water in the home cage. On these occasions, the rats in Groups OT-No Ext and $O$ always drank unflavored water.

Four days later, all rats were tested in the experimental chamber for $10 \mathrm{~min}$ with unflavored water given in presence of the odor cue. Two hours later, the rats were given 15 -min access to water in the home cage. Ten such tests were administered.

\section{Results and Discussion}

On the first day of conditioning, the rats in Groups OTExt and OT-No Ext did not differ reliably in mean intake of saccharin solution, 5.3 and $6.5 \mathrm{ml}$, respectively $(p>$.10). Group O drank a mean of $8.9 \mathrm{ml}$ of water, and Group No Li drank $6.7 \mathrm{ml}$; this difference was not reliable $(\mathrm{p}>.10)$.

On the second day of conditioning, the rats in Groups OT-Ext and OT-No Ext showed marked aversions to the odor-taste compound, with mean saccharin intakes of .1 and $.9 \mathrm{ml}$, respectively; the two groups did not differ reliably in mean intake $(p>.10)$. Group $O$ showed aversion to the odor cue; its mean 9.0-ml intake of water in the presence of the odor cue was significantly less than the 12.8-ml intake of Group No $\mathrm{Li}[\mathrm{t}(18)=2.58, \mathrm{p}<$ $.05]$.

During the period in which unreinforced exposures to saccharin solution were given without the odor cue, Group OT-Ext showed a strong aversion to saccharin, which gradually extinguished. On the first test, Group OT-Ext 
drank $1.8 \mathrm{ml}$, significantly less than the $10.6 \mathrm{ml}$ drunk by Group No $\mathrm{Li}$, which had never been exposed to saccharin solution before $[\mathrm{t}(18)=6.82, \mathrm{p}<.001]$. This aversion to saccharin persisted through the $21 \mathrm{~h}$ of continuous access; Group OT-Ext drank $37.8 \mathrm{ml}$, whereas Group No Li drank $51.8 \mathrm{ml}$. In the last of the three subsequent unreinforced exposures, the aversion seemed to have been extinguished; Group OT-Ext drank $12.0 \mathrm{ml}$, and Group No Li drank $12.3 \mathrm{ml}$.

Figure 1 shows the mean amount of water drunk in the presence of the almond odor by each group during 10 tests. Although an interval of 11 days separated the last conditioning trial from the first odor test, the three groups that received the odor cue paired with poison showed marked odor aversion. Of the 30 rats in these three groups, only 2 from Group $\mathrm{O}$ drank measurable amounts. Due to this floor effect, it was not possible to detect any differences among Groups OT-Ext, OT-No Ext, and O. After the first test, the pattern of results was consistent with the hypothesis of associative potentiation. During each of the next five tests, Groups OT-Ext and OT-No Ext showed marked potentiation of odor aversion. Each group drank significantly less unflavored water in the presence of the almond odor than did Group O (ps $<.05)$. This pattern, although attenuated by extinction, was evident during the remaining tests and also when the drinking scores were summed over the 10 tests: Group OT-Ext and OT-No Ext drank a total of 31.5 and $27.9 \mathrm{ml}$, respectively, whereas Group O drank $60.1 \mathrm{ml}$. Groups OT-Ext and OT-No Ext each differed reliably from Group O $[\mathrm{t}(18)=2.28, \mathrm{p}<.05$, and $\mathrm{t}(18)=2.68, \mathrm{p}<.05$, respectively], but did not differ from each other $(t<1.00)$.

Since extinction of the saccharin aversion prior to the testing of odor-aversion learning did not eliminate poten-

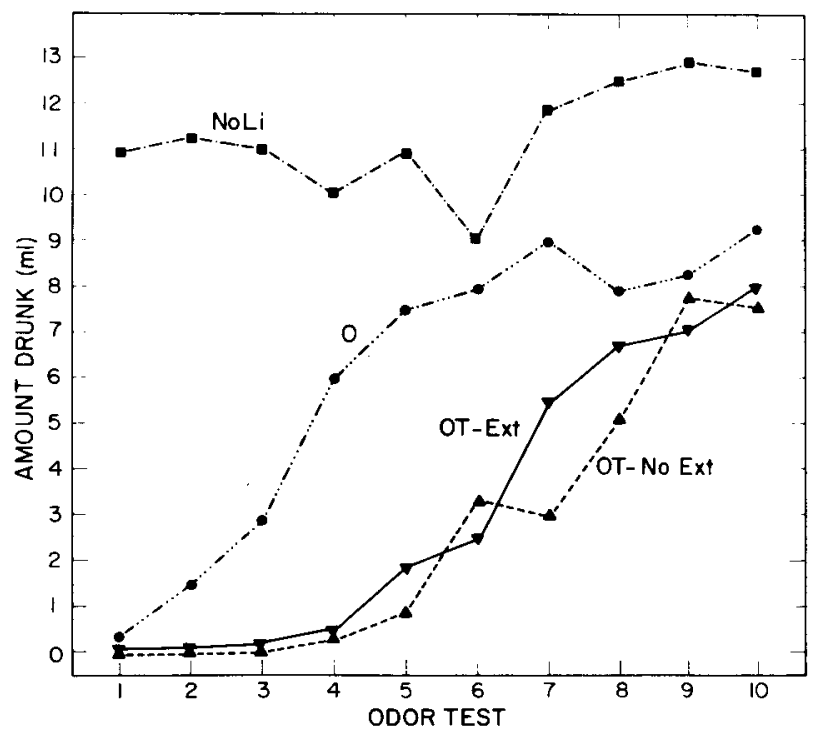

Figure 1. The mean amount of water drunk in the presence of the odor cue by the rats in Groups OT-Ext, OT-No Ext, and No Li during 10 tests. tiation, these results, like those of Palmerino (1979), show that the potentiation effect does not depend on an underlying taste aversion. In contrast to Palmerino's (1979) findings, moreover, extinction of the saccharin aversion had no detectable effect on the rate of extinction of the enhanced odor aversion. In none of the 10 tests with the odor cue was there a reliable difference between Groups OT-Ext and OT-No Ext (ts $\leq 1.01)$.

\section{EXPERIMENT 2}

The enhanced odor aversions obtained in Experiment 1 cannot be attributed to a summation (Durlach \& Rescorla, $1980)$ of the first-order associations: odor sickness and taste sickness. However, it could be argued that a secondorder association between odor and conditioned sickness was responsible for the strong odor aversions observed after extinction of the taste-sickness association. Since the procedure of Experiment 1, like that used by Palmerino (1979), involved two pairings of the almond-saccharin compound with lithium sickness, a second-order association between odor and conditioned sickness could, in theory, have occurred as follows. During the first pairing, of course, only first-order conditioning of the odorsickness and taste-sickness associations was possible. During the second pairing, however, in addition to first-order conditioning, the presentation of the almond-saccharin compound would constitute a second-order conditioning trial in which the second-order CS, the almond odor, would occur close together in time with the conditioned response of sickness evoked by the first-order CS, the saccharin taste. Extinction of the taste-sickness association might be expected to have little effect on the strength of an association between odor and conditioned sickness (Rizley \& Rescorla, 1972). In Experiment 2, only one pairing of the odor-taste compound with sickness was given to eliminate the possibility of second-order conditioning.

\section{Method}

Subjects. Forty male Sprague-Dawley rats, weighing approximately $211 \mathrm{~g}$ at the start of the experiment, were maintained on deionized water, as in Experiment 1.

Procedure. The procedure was similar to that used in Experiment 1 . The main modification was that there was only one pairing of the almond-saccharin compound with sickness. Briefly, the rats were acclimated to drinking in the experimental cages and then divided into four groups equated for water consumption: OT-Ext, OT-No Ext, O, and No Li. During aversion training, the rats in Groups OT-Ext and OT-No Ext received .1\% w/v saccharin solution in the presence of the almond odor for $10 \mathrm{~min}$ and were injected $30 \mathrm{~min}$ later with $1 \mathrm{ml}$ per $100 \mathrm{~g}$ of body weight of $.3 \mathrm{~N}$ lithium chloride. Group $\mathrm{O}$ drank deionized water in the presence of the almond odor prior to the injection of lithium. Rats in Group No Li drank saccharin solution in the presence of the almond but were not injected. As in Experiment 1, the almond odor was delivered on the disk surrounding the tip of the drinking spout.

Three days after conditioning, the rats in Groups OT-Ext and No Li were given saccharin solution in the experimental cages; the disks were unodorized. On the following day, these rats were given continuous access to the saccharin solution in the home cage for 
$24 \mathrm{~h}$. Then these rats were given saccharin solution for $10 \mathrm{~min}$ in the experimental cages on four additional occasions. The rats in Groups OT-No Ext and $O$ were similarly treated, except that they received only deionized water on these occasions. Five days after the last saccharin exposure, all rats were given three tests during which deionized water was given in the presence of the almond odor to test for odor aversion. Several days after the last odor test, all rats were tested with saccharin solution in the absence of the almond odor.

\section{Results and Discussion}

On the conditioning day, Groups OT-Ext, OT-No Ext, and No Li drank similar amounts of saccharin solution $(5.8,5.9$, and $6.6 \mathrm{ml}$, respectively), while Group O drank $8.6 \mathrm{ml}$ of deionized water. When unreinforced exposures to the saccharin solution were subsequently given in the absence of the odor cue, Group OT-Ext showed a strong taste aversion, which was gradually extinguished. During the first exposure, Group OT-Ext drank $1.5 \mathrm{ml}$, whereas Group No Li drank $11.2 \mathrm{ml}$ of saccharin solution $[\mathrm{t}(18)=16.24, \mathrm{p}<.001]$; Groups OT-No Ext and $\mathrm{O}$ drank 10.2 and $9.4 \mathrm{ml}$ of deionized water respectively. During the last saccharin test, Group OT-Ext drank $9.7 \mathrm{ml}$ and Group No Li, $10.3 \mathrm{ml}$; this difference was not statistically reliable $(\mathrm{t}<1.00)$.

Figure 2 shows the mean amount of deionized water drunk in the presence of the almond odor by each group of rats during three tests. During the first test, Groups OT-Ext and OT-No Ext both showed enhancement of odor aversion, with each group drinking significantly less unflavored water than did Group $\mathrm{O}[\mathrm{t}(18)=3.55$, $\mathrm{p}<$ .01 , and $\mathrm{t}(18)=2.17, \mathrm{p}<.05$, respectively]. This pattern, although progressively attenuated by extinction, is

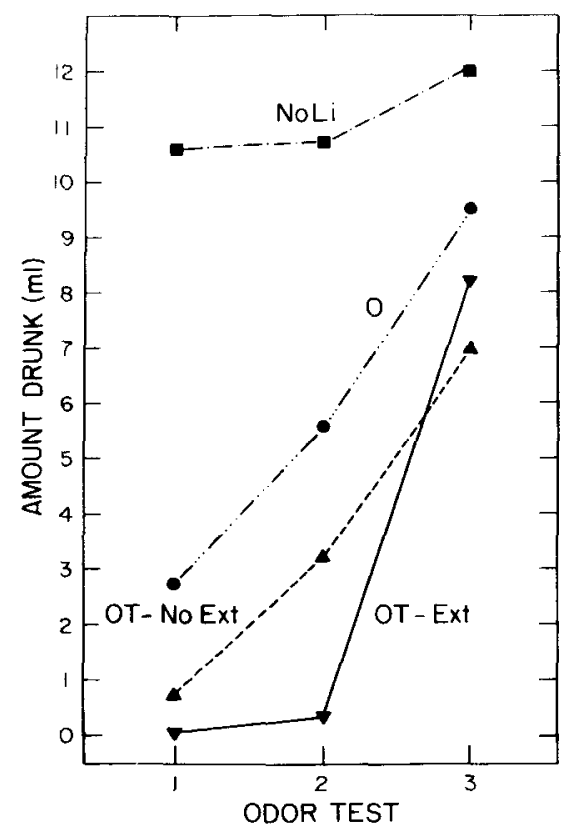

Figure 2. The mean amount of water drunk in the presence of the odor cue by rats in Groups OT-Ext, OT-No Ext, O, and No Li during three tests. apparent in each test and is also evident when the drinking scores are summed over the three tests: Groups OTExt and OT-No Ext drank a total of 8.5 and $10.9 \mathrm{ml}$, respectively, and Group O drank $17.8 \mathrm{ml}$. Groups OTExt and OT-No Ext each differed reliably from Group O $[\mathrm{t}(18)=3.73, \mathrm{p}<.01$, and $\mathrm{t}(18)=2.24, \mathrm{p}<.05$, respectively], but did not differ from each other $(\mathrm{t}<$ $1.00)$.

After the three odor tests, the rats were given a last test with saccharin solution. Group OT-No Ext drank $4.3 \mathrm{ml}$, whereas Group OT-Ext drank $10.5 \mathrm{ml}$, confirming that the two groups differed markedly in strength of saccharin aversion $[\mathrm{t}(18)=5.75, \mathrm{p}<.001]$. Groups $\mathrm{O}$ and No Li drank 10.5 and $12.8 \mathrm{ml}$, respectively; these groups differed reliably from Group OT-No Ext (ps < .01) but did not differ from each other or from Group OT-Ext (ps $>$ $.05)$.

As in Experiment 1, there was no evidence that extinction of the saccharin aversion facilitated extinction of the enhanced odor aversion. If anything, extinction of odor aversion seemed to occur more slowly in Group OT-Ext than in Group OT-No Ext. Thus, the present findings indicate that taste potentiation of odor aversion learning can occur in the absence of any detectable contribution by a within-compound association between odor and taste or by a second-order association between odor and a conditioned sickness response.

\section{EXPERIMENT 3}

Pigeons (Clarke et al., 1979; Lett, 1980; Westbrook et al., 1980) as well as quail (Lett, 1980) show taste potentiation of color-aversion learning. Using a procedure analogous to that used in Experiments 1 and 2, the purpose of Experiment 3 was to determine whether the potentiation of color aversion in pigeons depended upon the maintenance of a strong conditioned taste aversion.

\section{Method}

Subjects. Thirty adult pigeons of mixed sexes, breeds, and ages were housed in individual cages of the type used to keep commercial laying hens. Purina pigeon pellets were made available in a trough suspended outside the rear of the cage. Fluids were administered in a transparent, 7-oz plastic tumbler suspended at the front of the cage.

Materials. The stimulus solutions were red water and green water containing $1 \mathrm{ml}$ of Schwartz's food color per liter of tap water, vinegar water containing $10 \mathrm{ml}$ of Heinz distilled vinegar per liter of tap water, and red vinegar water containing $1 \mathrm{ml}$ of coloring and $10 \mathrm{ml}$ of vinegar per liter of tap water. The sickness-inducing agent was $.3 \mathrm{~N}$ lithium chloride solution injected intraperitoneally at a dose of $2 \mathrm{ml}$ per $100 \mathrm{~g}$ of body weight.

Procedure. First, the birds were habituated to a drinking schedule of $15 \mathrm{~min}$ daily access to water. They were divided into two groups: Group CT $(n=20)$ was to receive red vinegar paired with lithium toxicosis during conditioning, and Group $C(n=10)$ was to receive unflavored red water paired with lithium toxicosis. The two groups were equated for mean water consumption on the day prior to the first experimental treatment.

On the day preceding conditioning, the birds in Group CT were given unflavored green water for $15 \mathrm{~min}$. This was done to acclimatize the birds to drinking a novel solution in the hope of minimiz- 
ing neophobia on the training day. The birds in Group $\mathrm{C}$ were given vinegar solution; in addition to acclimatizing the birds to drinking a novel solution, this served to equate exposure to the vinegar cue in Groups CT and C. No injections were given.

The food troughs were removed approximately $2 \mathrm{~h}$ prior to the conditioning session to minimize the possibility of strong food aversions formed by adventitious pairing of food consumption and lithium poisoning. During conditioning, the birds in Group $\mathrm{C}$ were given red water for $15 \mathrm{~min}$, followed immediately by an injection of lithium chloride; the birds in Group CT drank red vinegar water for $15 \mathrm{~min}$ and then received the injection of lithium.

Starting approximately $4 \mathrm{~h}$ after all pigeons had been injected, both food and water were made continuously available for 5 days to facilitate recovery. After this recovery period, the birds were again allowed only 15-min daily access to water for 2 days to reestablish the deprivation schedule. Then Group CT was subdivided into two groups approximately matched for mean consumption on the day of conditioning: Group CT-E received unreinforced exposures to vinegar to extinguish the taste aversion; Group CT received water during this period. The extinction exposures consisted of a 15-min period of access, followed on the next day by a 24 -h period of access and then by two 15-min periods of access on each of the following days. A control comparison was provided by Group C, which also received vinegar water during this period. Extinction of the vinegar aversion was considered complete when Groups CT-E and $\mathrm{C}$ no longer differed in vinegar consumption.

On the day after the last extinction exposure, all birds were tested with unflavored red water for $15 \mathrm{~min}$. Since many of the birds drank little during the test, an additional 15 -min access to water was given to all birds approximately $4 \mathrm{~h}$ later. On the next day, the birds were given a final test with vinegar water for $15 \mathrm{~min}$.

\section{Results and Discussion}

Table 1 shows the amount of fluid drunk by each group during pretraining and training. During pretraining, Group C drank vinegar water, Groups CT and CT-E drank unflavored green water. As can be seen, the three groups drank similar amounts of fluid. During training, Group C drank unflavored red water while Groups CT and CT-E drank red vinegar water. The birds given red vinegar water drank marginally less than those given unflavored red water $[t(20)=2.02, p<.10]$. A similar effect has been observed in other studies (Lett, 1980; Wilcoxon, Dragoin, \& Kral, 1971). Most likely, the depression in the drinking of colored flavored water reflects a summation of the neophobia produced by each cue alone.

When subsequently given unreinforced exposures to uncolored vinegar water, Group CT-E showed reliable taste aversion learning that rapidly extinguished. During the first test, Group CT-E drank $7.6 \mathrm{ml}$, while Group C, which had previously been given vinegar water unpaired with sickness during the pretraining phase, drank $31.3 \mathrm{ml}$ $[t(18)=4.48, p<.001]$. The aversion was substantially attenuated by the $24 \mathrm{~h}$ of continuous exposure: Group

Table 1

Mean Amount (ml) of Fluid Drunk During Pretraining and Training by Each Group of Pigeons

\begin{tabular}{lcc}
\hline Group & Pretraining & Training \\
\hline C & 33.8 & 26.2 \\
CT & 38.3 & 19.2 \\
CT-E & 36.3 & 17.7 \\
\hline
\end{tabular}

CT-E drank $88.8 \mathrm{ml}$ and Group C, $98.1 \mathrm{ml}(\mathrm{t}<1.00)$. By the third and fourth exposures, virtually complete extinction of the vinegar aversions had occurred; on these two occasions, Group CT-E drank, respectively, 30.9 and $32.8 \mathrm{ml}$ and Group C drank, respectively, 31.2 and $33.0 \mathrm{ml}$.

On the next day, all birds were given a 15 -min test with unflavored red water. Groups CT-E and CT drank similar amounts of red water, 11.6 and $12.9 \mathrm{ml}$, respectively, whereas Group C drank $27.9 \mathrm{ml}$. Groups CT-E and CT did not differ from each other $(t<1.00)$, but each differed reliably from Group $\mathrm{C}[\mathrm{t}(18)=3.24, \mathrm{p}<.01$, and $\mathrm{t}(18)$ $=2.74, \mathrm{p}<.05$, respectively]. During a final test, all birds were given vinegar solution. Group CT drank $14.6 \mathrm{ml}$, substantially less than the $26.0 \mathrm{ml}$ drunk by Group C $[\mathrm{t}(18)=2.76, \mathrm{p}<.05]$ or the $23.8 \mathrm{ml}$ drunk by Group CT-E $[\mathrm{t}(18)=1.98, \mathrm{p}<.10]$; Groups CT-E and $C$ did not differ from each other $(t<1.00)$.

These results are similar to those obtained with rats. The presence of the taste cue during conditioning resulted in enhanced color aversions, although, for some unknown reason, the present potentiation effect was less marked than that reported earlier (Lett, 1980). Analogous to the results obtained studying taste potentiation of odor aversion in rats, the present results indicate that the potentiated color aversions did not depend on the maintenance of strong flavor aversions. Both Group CT-E, which received unreinforced exposures to vinegar water until virtually complete extinction of the vinegar aversion had occurred, and Group CT showed reliable and similar potentiation of aversion to red water.

\section{GENERAL DISCUSSION}

The present findings replicated and extended those of Palmerino (1979). The results of Experiments 1 and 2 showed that extinction of the conditioned saccharin aversion did not eliminate, or even attenuate, the enhanced almond aversion produced by compounding odor with taste during conditioning. In Experiment 3, analogous findings were obtained in pigeons. Extinction of the taste aversion did not attenuate the enhanced color aversion produced by compounding color with taste during conditioning. Thus, neither the enhancement of odor aversion in rats nor the color aversion in birds can be explained as a summation effect.

In contrast to the present findings and those of Palmerino (1979), Durlach and Rescorla (1980) found that extinction of the taste aversion eliminated enhancement of the odor aversion in rats. An examination of the Durlach and Rescorla procedure indicates that the discrepancy between their findings and those obtained in the present experiments and by Palmerino (1979) may be due to a critical difference between their procedure and ours. They gave their rats unreinforced exposures to the odortaste compound prior to conditioning. We did not do this, because such preexposures were not a feature of the original demonstrations of the taste potentiation effect (Clarke 
et al., 1979; Galef \& Osborne, 1978; Rusiniak et al., 1979) and were not required by the logic of the potentiation experiment. In any case, as explained below, this departure from earlier procedures makes the findings of Durlach and Rescorla (1980) of dubious relevance in explaining the taste potentiation effect demonstrated by others (e.g., Rusiniak et al., 1979).

The preconditioning exposures facilitated the formation of the odor-taste association (Durlach \& Rescorla, 1980; Rescorla \& Cunningham, 1978) and may even have been necessary for its occurrence, since acquisition of withincompound associations has been repeatedly shown to be disrupted by the subsequent occurrence of a US (Cheatle \& Rudy, 1979; Holland, 1984; Rudy, 1984). Such preexposures have also been shown to weaken enhancement of the odor aversion (Palmerino, 1979; Palmerino et al., 1980 ), suggesting that they tend to reduce the probability of associative potentiation. Thus, one explanation of the Durlach and Rescorla (1980) findings is that the enhanced odor aversions obtained under their conditions were due to a summation effect mediated by the odor-taste association rather than to associative potentiation. Another possibility is that the odor-taste association mediated a transfer of extinction from the taste aversion to the odor aversion. In a similar experiment with a taste-taste compound (Rescorla \& Cunningham, 1978), extinction of one taste element was shown to transfer to the associated taste, resulting in a reduced taste aversion. According to Rescorla and Cunningham (1978), this transfer was mediated by a within-compound association that may well have been formed during preconditioning exposures of the taste-taste compound rather than during the pairings of the compound with sickness. Such a transfer of extinction from the taste aversion to the odor aversionwould tend to mask any associative potentiation of aversion that might have been obtained by Durlach and Rescorla (1980).

As mentioned earlier, the original experiments demonstrating the taste potentiation effect did not include preconditioning exposures to the compound. Thus, to show that their findings were relevant in explaining the original potentiation experiments, Durlach and Rescorla (1980) needed to show that the within-compound associations they observed were formed mainly during the conditioning trial rather than during the preconditioning exposures. They provided no such evidence. In the last of their five experiments, Durlach and Rescorla did omit the preconditioning exposures to the odor-taste compound and, as would be expected on the basis of earlier demonstrations (e.g., Rusiniak et al., 1979), they obtained potentiation of odor aversion. They concluded that this experiment "implies that the within-compound associations responsible for potentiation can be formed rapidly and even with the occurrence of the US." Unfortunately, this conclusion is erroneous. Experiment 5 (Durlach \& Rescorla, 1980) merely shows that taste potentiation can occur without preexposures to the odor-taste compound; it does not imply that any within-compound learning occurred during the conditioning trial. To provide logically accept- able proof that within-compound associations are formed during conditioning and hence could be responsible for the original taste potentiation effect (Clarke et al., 1979; Galef \& Osborne, 1978; Rusiniak et al., 1979), Durlach and Rescorla should have repeated Experiment 5, in which no preexposures to the compound were administered, with suitable additional groups to show that extinction of the taste aversion eliminates enhancement of the odor aversion.

The present experiments and those of Palmerino (1979) have employed the necessary procedure (or an analogous procedure for birds) and have yielded results indicating that the taste potentiation effect is not produced by a summation process mediated by within-compound learning. The present findings complement those of Kiefer et al. (1982). As described earlier, they showed that rats with lesions of the gustatory neocortex that severely disrupt acquisition of the taste aversion show enhancement of odor aversion in the absence of any detectable conditioning of the taste aversion. Taken together, these findings provide strong evidence for the hypothesis of associative potentiation that the presence of the taste stimulus during conditioning results in a strengthening of the odor-sickness (or color-sickness) association.

\section{REFERENCES}

Braun, J. J., Slick, T. B., \& Lorden, J. F. (1972). Involvement of gustatory neocortex in the learning of taste aversions. Physiology \& Behavior, 9, 637-641.

Brett, L. P., Hankins, W. G., \& Garcia, J. (1976). Prey-lithium aversions. III. Buteo hawks. Behavioral Biology, 17, 87-98.

Cheatle, M. D., \& Rudy, J. W. (1979). Analysis of second-order odor aversion conditioning in neonatal rats: Implications for Kamin's blocking effect. Journal of Experimental Psychology: Animal Behavior Processes, 5, 142-151.

Clarke, J. C., Westbrook, R. F., \& Irwin, J. (1979). Potentiation instead of overshadowing in the pigeon. Behavioral and Neural Biology, 25, 18-29.

Durlach, P. J., \& Rescorla, R. A. (1980). Potentiation rather than overshadowing in flavor-aversion learning: An analysis in terms of within-compound associations. Journal of Experimental Psychology: Animal Behavior Processes, 6, 175-187.

GALEF, B. G., JR., \& OSBORNE, B. (1978). Novel taste facilitation of the association of visual cues with toxicosis in rats. Journal of Comparative and Physiological Psychology, 92, 906-916.

GARCIA, J., RusiniaK, K. W. (1980). What the nose learns from the mouth. In D. Muller-Schwarze \& R. M. Silverstein (Eds.), Chemical signals. New York: Plenum Press.

HollaND, P. C. (1984). First- and second-order responding in appetitive serial compound conditioning. In M. L. Commons, R. J. Herrnstein \& A. R. Wagner (Eds.), Quantitative analyses of behavior: Vol. 3. Acquisition. Cambridge: Ballinger.

Kamin, L. J. (1969). Predictability, surprise, attention, and conditioning. In B. A. Campbell \& R. M. Church (Eds.), Punishment and aversive behavior. New York: Appleton-Century-Crofts.

Kiefer, S.W., Rusiniak, K. W., \& Garcia, J. (1982). Flavor-illness aversions: Gustatory neocortex ablations disrupt taste but not tastepotentiated odor cues. Journal of Comparative and Physiological Psychology, 96, 540-548.

LETT, B. T. (1980). Taste potentiates color-sickness associations in pigeons and quail. Animal Learning \& Behavior, 8, 193-198.

LETT, B. T. (1984). Taste potentiation in poison avoidance learning. In_M. L. Commons, R. J. Herrnstein, \& A. R. Wagner (Eds.), Quan- 
titative analyses of behavior: Vol. 3. Acquisition. Cambridge: Ballinger.

Miles, C. G., \& Jenkins, H. M. (1973). Overshadowing in operant conditioning as a function of discriminability. Learning and Motivation, 4, 11-27.

PALMERINo, C. C. (1979). Associative interactions of odor and taste in illness-induced aversions. Unpublished doctoral dissertation, University of California, Los Angeles, California.

Palmerino, C. C., Rusiniak, K. W., \& Garcia, J. (1980). Flavorillness aversions: The roles of odor and taste in memory for poison. Science, 208, 753-755.

Pavlov, I. P. (1927). Conditioned reflexes (G. V. Anrep, Trans.) London: Oxford University Press.

Rescorla, R. A., \& CunNINGHAM, C. L. (1978). Within-compound flavor associations. Journal of Experimental Psychology: Animal Behavior Processes, 4, 267-275.

Rescorla, R. A., \& Wagner, A. R. (1972). A theory of Pavlovian conditioning: Variations in the effectiveness of reinforcement and nonreinforcement. In A. H. Black \& W. F. Prokasy (Eds.), Classical conditioning II: Current research and theory. New York: AppletonCentury-Crofts.

REVUSKY, S. (1971). The role of interference in association over a delay. In W. K. Honig \& P. H. R. James (Eds.), Animal memory. New York: Academic Press.
Rizley, R. C., \& Rescorla, R. A. (1972). Associations in secondorder conditioning and sensory preconditioning. Journal of Comparative and Physiological Psychology, 81, 1-11.

RuDY, J. (1984). An appreciation of higher-order conditioning and blocking. In M. L. Commons, R. J. Herrnstein, \& A. R. Wagner (Eds.), Quantitative analyses of behavior: Vol. 3. Acquisition. Cambridge: Ballinger.

Rusiniak, K. W., Hankins, W. G., Garcia, J., \& Brett, L. P. (1979). Flavor-illness aversions: Potentiation of odor by taste in rats. Behavioral and Neural Biology, 25, 1-17.

Westbrook, R. F., Clarke, J. C., \& Provost, S. (1980). Long-delay learning in the pigeon: Flavor, color and flavor-mediated color aversions. Behavioral and Neural Biology, 28, 398-407.

Westbrook, R. F., Homewood, J., Horn, K., \& Clarke, J. C. (1983). Flavour-odour conditioning: Odour-potentiation and flavourattenuation. Quarterly Journal of Experimental Psychology, 35B, 13-33.

Wilcoxon, H.C., Dragoin, W. B., \& Kral, P.A. (1971). Illnessinduced aversions in rats and quail: Relative salience of visual and gustatory cues. Science, 171, 826-828.

(Manuscript received November 4, 1983; revision accepted for publication August 7, 1984). 